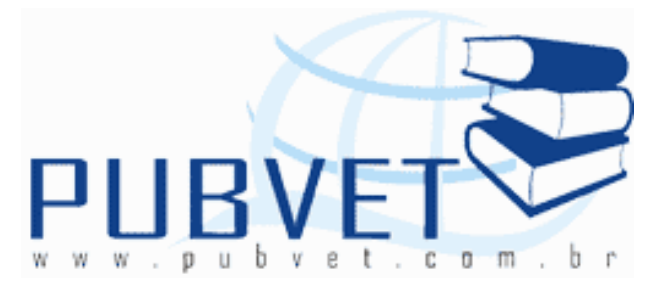

PUBVET, Publicações em Medicina Veterinária e Zootecnia.

\title{
Caracterização do convívio entre o proprietário e o cão atendido no hospital veterinário da Universidade Federal de Uberlândia
}

Jordana Almeida Santana ${ }^{1}$, Igor Paula De Castro $^{1}$ e Laerte Pereira de Almeida ${ }^{2}$

${ }^{1}$ Faculdade de Medicina Veterinária, Universidade Federal de Uberlândia, Av. Pará, 1720 - Campus Umuarama - Bloco 2T., Uberlândia, MG., Cep: 38400902.*e-mail: jojo_2805@hotmail.com.

${ }^{2}$ Faculdade de Medicina Veterinária, Universidade Federal de Uberlândia, Av. Pará, 1720 - Campus Umuarama - Bloco 2T.Uberlândia, MG, Cep: 38400-902.

\section{Resumo}

A crescente urbanização tem aumentado a proximidade das pessoas com os cães. Uma interação inadequada entre eles pode ser a causa de vários distúrbios de comportamento, como a agressão, tanto por parte do homem, quanto do animal. Deste modo, propôs-se a realização de uma pesquisa para avaliar o manejo e a interação entre os cães e seus proprietários, determinando assim, a relação e o convívio entre os mesmos. Foram entrevistados 249 proprietários de cães no Hospital Veterinário da UFU, no período de agosto de 2008 à março de 2009. Após a coleta, os dados foram digitados para um banco de dados, criado por meio do software EpiInfo 6.04, para análise. Os resultados mostraram que dos 249 proprietários entrevistados, $53,4 \%$ possuem cães fêmeas, o que pode revelar certa preferência por esse sexo, pois são mais afetivas e mais obedientes que os 
SANTANA, J.A., CASTRO, I.P. e ALMEIDA, L.P. Caracterização do convívio entre o proprietário e o cão atendido no hospital veterinário da Universidade Federal de Uberlândia. PUBVET, Londrina, V. 4, N. 7, Ed. 112, Art. 757, 2010.

cães machos. $41,8 \%$ dos cães são criados fora de casa. 16,1\% dos cães saem sozinhos para a rua, $30,5 \%$ estão com a vacinação incompleta ou nunca foram vacinados, tendo-se um perigo exposto à sociedade, já que são eles os reservatórios e transmissores de diversas zoonoses. 15,7\% dos cães são desobedientes, o que agrava mais o risco, já que fogem freqüentemente. $71,1 \%$ dos proprietários passeiam com seu cão, e destes, 19,6\% não utilizam coleira, o que é proibido para algumas raças. $14,7 \%$ dos que passeiam dizem passear raramente, o que sugere uma relação distante com seu animal. 77,5\% dos proprietários disseram que várias pessoas da família cuidam do cão e, $47,8 \%$ dos $91,6 \%$ brincam com seus animais, e o fazem mais de uma vez ao dia. Deste modo, conclui-se que existe uma relação distante entre os proprietários e os animais estudados e, que os animais atendidos no Hospital Veterinário não têm um manejo adequado, o que deve ser corrigido com Educação Sanitária.

Palavras-chave: Agressividade canina, interação homem-cão, epidemiologia, comportamento animal

\title{
Characterization of interaction between owner and dog treated at the veterinary hospital of Federal University of Uberlândia
}

\begin{abstract}
Increasing urbanization has increased the proximity of people with dogs. An inappropriate interaction between them can be the cause of several behavioral disorders such as aggression and depression by both the man and the animal. Thus, we proposed to conduct a survey to assess the management and interaction between dogs and their owners, thereby determining the relationship and interaction between them. We interviewed 249 owners of dogs in the Veterinary Hospital of UFU, from August 2008 to March 2009. After collection, the data were entered into a database, created by the software 6.04 software for analysis. The results showed that the 249 owners interviewed,
\end{abstract}


SANTANA, J.A., CASTRO, I.P. e ALMEIDA, L.P. Caracterização do convívio entre o proprietário e o cão atendido no hospital veterinário da Universidade Federal de Uberlândia. PUBVET, Londrina, V. 4, N. 7, Ed. 112, Art. 757, 2010.

$53.4 \%$ are female dogs, which may reveal some preference for the sex, because they are more caring and more obedient to the dogs. $41.8 \%$ of dogs are bred outside the home. $16.1 \%$ of the dogs out into the street alone, $30.5 \%$ from vaccination are incomplete or have never been vaccinated and is exposed to a danger to society, since they are the reservoirs and transmitters of several zoonoses. $15.7 \%$ of dogs are disobedient, which increases the risk more, as often flee. $71.1 \%$ of the owners walk with your dog, and of these, $19.6 \%$ do not use a leash, which is forbidden for some breeds. $14.7 \%$ of the pacing rarely say walk, which suggests a distant relationship with your pet. $77.5 \%$ of owners said several family members take care of the dog, and $47.8 \%$ from $91.6 \%$ play with their animals, and do more than once a day. Therefore, we conclude that there is a distant relationship between the owners and the animals studied, and the animals treated at the Veterinary Hospital does not have an adequate management, which should be corrected with Health Education.

Keywords: Aggression canine, human-dog, epidemiology, animal behavior

\section{INTRODUÇÃO}

A crescente urbanização e o aglomeramento nos centros urbanos têm aumentado a proximidade das pessoas com os animais de companhia, colocando-os dentro de casa e mudando muitos de seus hábitos instintivos (Faraco; Seminotti, 2004). São considerados membros da família, e ao mesmo tempo, objetos a serem venerados e amados, com direito a cuidados de saúde e estética, adotando a posição de seres essenciais na rotina humana (Jensen; Pauly, 1998).

O convívio entre cães e homens tende a crescer cada vez mais nas sociedades atuais. Aceito como seu "melhor amigo", o cão há vários séculos conquistou seu lugar na sociedade humana. Segundo Rondinoni (2000), pessoas e cães podem conviver juntos pelo fato de possuírem sistemas sociais 
SANTANA, J.A., CASTRO, I.P. e ALMEIDA, L.P. Caracterização do convívio entre o proprietário e o cão atendido no hospital veterinário da Universidade Federal de Uberlândia. PUBVET, Londrina, V. 4, N. 7, Ed. 112, Art. 757, 2010.

muito semelhantes, sendo este um dos motivos de conflitos entre os mesmos, pois as pessoas interpretam os sinais caninos como se fossem humanos.

Uma interação inadequada entre homens e animais de estimação pode ser a causa de vários distúrbios de comportamento descritos, como por exemplo, a agressão (Froes et al., 2007).

O cão pode apresentar diversas reações perante situações diferentes no seu dia-a-dia. Com a domesticação, ele perdeu alguns de seus hábitos, mas mantém seus instintos ainda guardados, incluindo a agressividade, como fator de sobrevivência (Rossi, 1999).

Quando um cão manifesta comportamento de agressividade, sinaliza sua condição de insatisfação ou descontentamento por meio de uma série de sinais. Caso a agressão se consuma, será pela falta de percepção ou incorreta interpretação desses sinais. Nesse sentido, dizer que um cachorro é agressivo em termos gerais, não quer dizer absolutamente nada. É necessário entender quando ou em quais situações o cachorro é agressivo. Desse modo, deve-se avaliar individualmente o caso, para poder abordar essa agressividade (Lantzman, 2008).

Ciampo et al. (2000) denotam que pessoas adultas, crianças, conhecidos, desconhecidos, proprietários ou visitantes podem ser alvo dessas reações, e são atacadas quando o animal se sente ameaçado e sem maneiras de se defender.

O homem é reconhecido pelo cão como integrante da matilha, o que o inclui nessa relação de hierarquia. Cães com tendência dominante apresentam sinais indicativos desde filhotes. Desse modo, o proprietário deve adotar a posição de dominância, já que é o mentor das regras (Pizzolatto, 2006).

As condições de vida do animal podem contribuir para o desenvolvimento da agressividade. Ele deve ter um local adequado para alimentação, alimentarse nos horários recomendados, ter água limpa e filtrada em abundância, ter brinquedos para sua distração, carinho, entre outros. A falta de um ambiente 
SANTANA, J.A., CASTRO, I.P. e ALMEIDA, L.P. Caracterização do convívio entre o proprietário e o cão atendido no hospital veterinário da Universidade Federal de Uberlândia. PUBVET, Londrina, V. 4, N. 7, Ed. 112, Art. 757, 2010.

que proporcione aos filhotes contato com outras pessoas e outros animais também é importante no desvio de suas condutas funcionais (Rossi, 1999).

A relação entre homem e cão deve ser harmônica e prazerosa e, agressão e maus tratos traduzem a quebra da harmonia dessa relação (Beaver, 2001). Com base nestes fatos é que se realizou uma pesquisa para avaliar algumas características presentes no convívio entre cães e proprietários, com uma amostra de cães atendidos no Hospital veterinário da UFU.

\section{MATERIAL E MÉTODOS}

\subsection{População de Estudo}

Para o desenvolvimento desta pesquisa foi escolhida como População de Estudo cães atendidos no Hospital Veterinário da UFU, sendo escolhida uma amostra de conveniência.

\subsection{Coleta de Dados}

Foram selecionados e coletados dados de 249 cães por meio de um questionário padronizado, previamente testado e codificado, contendo dados sobre os cães: raça, sexo, idade, aspectos do manejo, da interação entre homem e animal, do domicilio do animal e referente ao proprietário. Os dados foram coletados por estudantes de Medicina Veterinária, submetidos a treinamento prévio, por meio de entrevistas realizadas, no Hospital Veterinário, com o proprietário do cão e os outros dados foram obtidos da ficha clinica do animal atendido. 
SANTANA, J.A., CASTRO, I.P. e ALMEIDA, L.P. Caracterização do convívio entre o proprietário e o cão atendido no hospital veterinário da Universidade Federal de Uberlândia. PUBVET, Londrina, V. 4, N. 7, Ed. 112, Art. 757, 2010.

\subsection{Processamento e Análise dos Dados}

Os dados coletados foram duplamente digitados para um banco de dados, criado por meio do software EpiInfo 6.04, e, após serem submetidos a controle de qualidade os dados foram analisados estatisticamente. Na análise, os dados foram dispostos em tabelas, sendo estimadas as respectivas freqüências das variáveis estudadas.

\section{RESULTADOS E DISCUSSÃO}

\subsection{Dados referentes aos cães.}

Tabela 1 - Dados referentes aos cães avaliados. Uberlândia-MG, 2008.

\begin{tabular}{lcc}
\hline \multicolumn{1}{c}{ Variável } & $\begin{array}{c}\text { Número } \\
\text { de cães }\end{array}$ & Porcentagem(\%) \\
\hline $\begin{array}{l}\text { Sexo } \\
\text { Fêmea }\end{array}$ & & \\
Macho & 133 & 53,4 \\
& 116 & 46,6 \\
Idade (anos) & & \\
S1 & 49 & 19,8 \\
2 a 4 & 86 & 34,6 \\
5 a 8 & 76 & 30,4 \\
> 8 & 38 & 15,2 \\
O Cão é adestrado & & \\
Sim & 17 & 6,8 \\
Não & 232 & 93,2 \\
& & \\
O cão é vacinado & & \\
Sim (vacinação completa) & 170 & 68,3 \\
Sim (vacinação incompleta) & 65 & 4,4 \\
Não (nunca foi vacinado) & 11 & 1,2 \\
Não sabe informar & 3 & \\
& & \\
& &
\end{tabular}


SANTANA, J.A., CASTRO, I.P. e ALMEIDA, L.P. Caracterização do convívio entre o proprietário e o cão atendido no hospital veterinário da Universidade Federal de Uberlândia. PUBVET, Londrina, V. 4, N. 7, Ed. 112, Art. 757, 2010.

Tabela 2 - Dados referentes à função social do animal. Uberlândia-MG, 2008.

Variável

Local de criação do cão

Dentro de casa

Fora de casa

Dentro e fora de casa

Modo de Criação do cão

Preso

Solto

\section{Função do cão em casa}

Guarda

Companhia

Guarda e companhia

O cão sai sozinho para a rua

Sim

Não

O cão é considerado:

Obediente e manso

Obediente e bravo

Desobediente e manso

Desobediente e bravo

Não sabe informar

\section{Número de cães Porcentagem}

(\%)

$\begin{array}{cc}52 & 20,9 \\ 104 & 41,8 \\ 93 & 37,3\end{array}$

229

20

92

8

22

111

116

8,8

44,6

46,6

40

16,1

209

83,9

155

51

33

6

4
62,2

20,5

13,3

2,4

1,6

$\mathrm{Na}$ tabela 1, podemos observar que dos 249 proprietários entrevistados, $53,4 \%$ possuem cães fêmeas, o que pode revelar certa preferência por esse sexo na escolha do animal, especialmente quando associamos que a maioria dos cães em questão são utilizados como animais de companhia ou de guarda e companhia concomitantemente, o que justifica a analogia de Fogle (2006), que relata que as fêmeas são mais afetivas, mais obedientes, menos destrutivas e necessitam de mais atenção que os cães machos. 
SANTANA, J.A., CASTRO, I.P. e ALMEIDA, L.P. Caracterização do convívio entre o proprietário e o cão atendido no hospital veterinário da Universidade Federal de Uberlândia. PUBVET, Londrina, V. 4, N. 7, Ed. 112, Art. 757, 2010.

No entanto, mesmo que as maiores freqüências tenham sido de raças pequenas e de cães utilizados para companhia, observa-se que $41,8 \%$ dos cães são criados fora de casa (tabela 2 ), o que constitui uma relação mais distante entre proprietário e cão. Outra informação relevante é o fato de que $16,1 \%$ dos cães saem sozinhos para a rua e, associando aos dados da tabela 1 que mostram que $30,5 \%$ estão com a vacinação incompleta ou nunca foram vacinados, tem-se um perigo exposto à sociedade, já que são eles os reservatórios e transmissores de diversas zoonoses. É neste contexto em que há a preocupação com a Raiva, que segundo Rocha (2003) é provocada, principalmente, por cães não vacinados. Considerando que $15,7 \%$ dos cães são desobedientes (tabela 2), agrava-se mais o risco, já que animais que não respeitam o dono fogem freqüentemente, podendo ser vítima dessa falta de educação sanitária associada ao manejo inadequado pelo proprietário.

Tabela 3 - Dados referentes a passeios do cão. Uberlândia - MG, 2008.

Variável

Costuma passear com o cão

Sim

Não

$1-3$ vezes por dia

1-4 vezes por semana

Raramente
Freqüência de passeios com o cão

Número Porcentagem (\%)
177

72

58

93

26

144

35
71,1

28,9

\section{O cão passeia utilizando coleira}

Sim

Não
32,8

52,5

14,7

80,4

19,6

Na tabela 3, nota-se que dos indivíduos entrevistados, $71,1 \%$ passeiam com seu cão, e destes, 19,6\% não utilizam coleira, o que é proibido para 
SANTANA, J.A., CASTRO, I.P. e ALMEIDA, L.P. Caracterização do convívio entre o proprietário e o cão atendido no hospital veterinário da Universidade Federal de Uberlândia. PUBVET, Londrina, V. 4, N. 7, Ed. 112, Art. 757, 2010.

algumas raças com a legislação em vigor do Ministério da Agricultura, Desenvolvimento Rural e Pescado (DECRETOS-LEI No 312/2003; 313/2003; E 315/2003 DO DR No 290 SÉRIE I-A DE 17/12/2003 - MADRP), que determina o uso obrigatório de focinheira, coleira, guia curta e enforcador para as raças pit bull, rowailler, mastin napolitano, pastor alemão, bull terrier, fila brasileiro, doberman ou animais que pesam mais de 20 quilos. Já dito que há uma porcentagem significativa de cães não vacinados, aumenta o risco de exposição da população, pois os mesmos podem ser transmissores de doenças (Rocha, 2003). Não podemos esquecer que $14,7 \%$ dos proprietários que passeiam com seus cães, dizem passear raramente, o que novamente sugere uma relação distante com seu animal.

\subsection{Caracterização da Interação entre o Proprietário e seu Cão}

Tabela 4 - Dados referentes à interação Proprietário e cão, Uberlândia-MG, 2008.

\begin{tabular}{lcc}
\hline \multicolumn{1}{c}{ Variável } & Número & Porcentagem (\%) \\
\hline $\begin{array}{l}\text { Quem cuida do cão } \\
\text { Só o entrevistado }\end{array}$ & 40 & \\
$\begin{array}{l}\text { Outro membro da família } \\
\text { Várias pessoas da família }\end{array}$ & 16 & 16,1 \\
& 193 & 6,4 \\
Costuma brincar com o & & 77,5 \\
cão & & \\
Sim & 228 & \\
Não & 21 & 91,6 \\
& & 8,4 \\
Freqüência que costuma & & \\
brincar com o cão & 109 & 47,8 \\
Mais de 1 vez por dia & 45 & 19,8 \\
1 vez por dia & 49 & 21,5 \\
2-3 vezes por semana & 25 & 10,9 \\
Só quando chega em casa & & \\
& & \\
\hline
\end{tabular}


SANTANA, J.A., CASTRO, I.P. e ALMEIDA, L.P. Caracterização do convívio entre o proprietário e o cão atendido no hospital veterinário da Universidade Federal de Uberlândia. PUBVET, Londrina, V. 4, N. 7, Ed. 112, Art. 757, 2010.

$\mathrm{Na}$ tabela 4, pode-se observar que dos 249 proprietários entrevistados, $77,5 \%$ responderam que várias pessoas da família cuidam do cão e, 47,8\% dos $91,6 \%$ brincam com seus animais, e o fazem mais de uma vez ao dia. Rossi (1999) relata que muitas vezes, distúrbios como a agressividade depende do tratamento do dono, que pode levar a uma reação recíproca do animal, demonstrando que a agressividade pode ser reflexa do ambiente em que o cão é criado, havendo influência em seu temperamento. O cão precisa reconhecer o dono como integrante de sua matilha para manter seu equilíbrio psicológico e para isso, o dono deve reconhecer a melhor forma de interagir com seu cão. Do contrário, observamos distúrbios comportamentais destrutivos e agressivos (Resende; Machado; Muzzi, 2006). A falta de um ambiente ideal que imponha aos cães seus limites é causa importante dos desvios de comportamento agressivos, pois as condições de vida do animal podem contribuir para manifestações de agressividade (Viaro, 2004).

\section{CONCLUSÕES}

O manejo dos cães pesquisados está inadequado, podendo propiciar situações que incrementem a agressividade do animal ou do próprio proprietário. Alguns proprietários deixam evidente a má interação com seus animais de estimação, o que pode indicar necessidades físicas e psicológicas não atendidas, podendo ser um motivo no desenvolvimento da agressividade.

\section{REFERÊNCIAS BIBLIOGRÁFICAS}

Beaver, B. V., Comportamento canino: um guia para veterinário. São Paulo: Roca, 2001.

Ciampo, L. A D; Riccoa, R. G; Almeida, C. A. N; Bonilhac, L. R. C. M; Santos, T. C. C. Acidentes de mordeduras de cães na infância. Revista de Saúde Pública, São Paulo v. 34, no 4, p. 411-412, 2000.

Faraco, C.B.; Seminotti, N. A relação homem-animal e a pratica veterinária. Revista do Conselho Federal de Medicina Veterinária, v.1, n. 32, p.57-62, 2004. 
SANTANA, J.A., CASTRO, I.P. e ALMEIDA, L.P. Caracterização do convívio entre o proprietário e o cão atendido no hospital veterinário da Universidade Federal de Uberlândia. PUBVET, Londrina, V. 4, N. 7, Ed. 112, Art. 757, 2010.

Fogle, B. Escolhendo um cão, Dicas de Comportamento, 2006. Disponível em:http://www.dogwalker.com.br/dicas/index.php?id=14\&category=1\&titulo=Escolhendo\%20 um\%20c\%C3\%A3o Acesso em: 22 abr. 2008

Froes, T.R.; Wouk, A.F.P.F.; Sillas, T.; Doro, J.R.; Klaumann, P.R. Transtorno obssessivocompulsivo como causa de formação de tricobenzoar em cão: relato de caso. Revista Clinica Veterinária, v.12, n.67, p.55-58, 2007.

Jensen, J. ;Pauly, J. J. Imaginar a la audiencia: pérdidas y ganancias em los estudios culturales. In: Fergunson, M. E Golding, P. (eds). Economía política y estudios culturales. Barcelona: Bosch Casa Editorial, p. 263-282, 1998.

Lantzman, M. in Agressão canina, 2008. Disponível em: http://www.saudeanimal.com/artig167.htm Acesso em: 20 abr. 2008.

Pizzolatto, C. Cães de Companhia, 2006. Disponível em: http://www.bitcao.com.br/cachorro15.htm?UID Acesso em 21 abr. 2008.

Rocha, R. R. Relação Homem-Animal e Agressividade Canina. 2003. 32 f. Monografia (Graduação em Medicina Veterinária) - Faculdade de Medicina Veterinária, Universidade Federal de Uberlândia, Uberlândia, 2003.

RondidoniI, G. F. A domesticação do cão, seu comportamento agressivo e seu tratamento, 2000. Disponível em<http://www.redevet.com.br/artigos/domest1.htm> Acesso em 20 abr. 2008.

Resende, D. M.; Machado, H. H. S.; Muzzi, R. A. L. Manejo de Cães, 2006. Disponível em: http://www.editora.ufla.br/Boletim/pdfextensao/bol_08.pdf Acesso em: 22 abr. 2008

Rossi, A. In: Adestramento Inteligente. São Paulo: CMS, p.260, 1999.

Viaro, O. Manual do Educador, Criando um amigo. Centro de Controle de Zoonoses, Gerência de Vigilância Ambiental, Secretaria Municipal da Saúde, Prefeitura do Município de São Paulo, 2004. 